\title{
The Countermeasures of Officials Just Going through the Motions under the New Normal*
}

\author{
Jie $\mathrm{Gu}$ \\ Wuhan University of Science and Technology \\ Wuhan, China 430000
}

\author{
Zeng Wang \\ Wuhan University of Science and Technology \\ Wuhan, China 430000
}

\begin{abstract}
At present, the governments from central to local comprehensively strengthen party discipline and constantly advance anti-corruption and accountability. However, the phenomenon of officials just going through the motions is increasingly serious, especially in the critical period of deepening reform. Governments in all the regions are actively exploring effective measures for the phenomenon of officials just going through the motions and the inaction of cadres, which is a challenge that restricts the reform and development of the country. Hence, through the analysis of the specific forms and the causes of the phenomenon, the paper puts forward countermeasures and suggestions for officials just going through the motions combined with current situation.
\end{abstract}

Keywords-strengthen party discipline; officials just going through the motions; causes; countermeasures

\section{INTRODUCTION}

Since the Eighteenth National Congress, the central government has issued a number of regulations and prohibitions such as "eight regulations", and carried out a series of actions in rectifying party's styles such as "three strictness and honesty". In the reinforcement of anti-corruption and accountability, the phenomenon that officials just go through the motions is prominent gradually, which not only affects the credibility and image of the government, reduce the administrative efficiency and the effect of anti-corruption, but impedes the process and effects of comprehensive deepening reform. Therefore, it's very urgent to solve the problem of officials just going through the motions.

\section{THE PERFORMANCE OF OFFICIALS JUST GOING THROUGH THE MOTIONS}

The phenomenon of some officials just going through the motions has existed from ancient times. In the past, the phenomenon of officials' random acts is very common in loose officialdom, while nonfeasance is few. At present, under the background of governments from the central to the local comprehensively strengthening party discipline and governing officials strictly, some leading cadres find it is difficult to adapt to the new normal, so they lose the responsibility and

*This paper is the achievement of Students Research Fund Project of Wuhan University of Science and Technology (a) "governing officials just going through the motions strictly, and building clean and promising cadres".

Gu Jie, Ph.D supervisor, master's supervisor in Wuhan University of Science and Technology, Hubei provincial decision support expert, President of the Hubei Provincial Institute of administrative management.Wang Zeng, master of public administration, School of Literature, Law and Economics, Wuhan University of Science and Technology. power of leadership gradually, and then take non-action in their duties. The specific practices can be reduced to three aspects: unwilling to do, incapable of doing, and dare not to do.

\section{A. Unwilling to Do}

1) Unwilling to do because they are satisfied with the existing state

Some leading cadres occupy their positions but do not consider the policies, lack sense of responsibility and service consciousness: they remain in a proper sphere only to enjoy without considering devotion; lacking goals, and they put on the appearance of being busy but dawdle all days, keeping the same year after year.

2) Unwilling to do because they are negative observers

This kind of cadres have something in common that they are selective in handling affairs, unwilling to bear hardships, avoid heavy responsibility as much as possible, while for the simple and profitable things, they are willing to do, and adopt negative attitude towards complicated things of non-profit, worrying about personal gains and losses, even "do tai chi", finding an excuse to refuse to bear responsibility.

3) Unwilling to do because they are concerned for personal gains and losses

On account of rectifying party styles strictly at present, many hidden benefits in the past are gradually standardized and many unspoken rules are broken, some party members and cadres have cognitive and emotional biases for the new normal of strengthening party discipline. They concern more about personal interests regardless of interests of the public, being irresponsible for their duties as well as lacking entrepreneurial enthusiasm

\section{B. Dare Not to Do}

1) Dare not to do because they are afraid of taking risks and responsibilities

Some cadres are afraid of taking responsibilities. They are afraid of taking responsibilities in accordance with policies, thinking that "the more they work, the more troubles they will have". To be peaceful officers is all they want, they do as little as possible, resolutely refuse to do anything bearing risk, being afraid of accountability and daring not to do any important tasks. 
2) Dare not to do because they are afraid of offending people

Some cadres worry too much in the process of working, and they hold their tongues faced with unfairness, going around when encountering conflicts. Because of fearing offending people and endangering themselves, they yield to bad practice blindly and let the things they should supervise and deal with alone as well as adopt non-action attitudes.

3) Dare not to do because they are afraid of exposure and hype

Some cadres are not good in handling affairs under the supervision of the public and media, they are worried about being in the forefront of public opinions because of bad work, and getting involved in the Internet storm. As a result, they keep a good distance from difficult problems and adopt negative attitudes.

\section{Incapable of Doing}

1) Incapable of doing because of their ossification of thinking

Some officials handle affairs relying on their experience and sensation and take the road of dogmatism. They are at loss end facing new tasks and situations. They work completely relying on meeting, use meetings to carry out meetings and documents to implement documents. However, they disapprove of the study of party theories and modern scientific knowledge, and their thinking can not keep up with the development of society.

\section{2) Incapable of doing because of the lack of ability}

Personal comprehensive abilities of some party members and cadres are deficient, which lead to their lagging behind the new situation. With the constant development of society, the requirements of the abilities of solving new problems and finishing new tasks are also constantly improved, so party members and cadres not only need to pay close attention to the change of situation, but continue to learn to meet the needs of the work. They should work hard to avoid the situation, in which old solutions can not solve new problems while new approaches are not available and wicked problems can not be solved.

\section{3) Incapable of doing because of impractical style}

Some cadres are keen to listen to the report in the office, and they know little about the practical situation of the grass roots. It results in that their decisions based on experience lack combination with actual situation, even are completely divorced from the reality. Therefore, it deviates from policy in the implementation, lack experience in solving concrete problems of the grassroots, and depart from the principle of being realistic in everything one does.

\section{4) Dilatory and slow work styles}

Some officials carry out tasks that superiors arrange slowly, and they lack effective proactivity, trying their best to delay work against them. They can not promptly solve the urgent problems that the public reflect strongly, and various complex approval procedures also delay the best time to solve the problems. What's worse, some officials take tardiness as the means of making profit.

\section{ThE CAUSE OF OfFICIALS JUST GOING THROUGH THE MOTIONS}

\section{A. Subjective Reason}

1) The thinking of "official standard" is severe; the sense of responsibility is weak

A small number of cadres are indulged in the thought of "official standard" in the past, and put too much emphasis on the "official position". They are immersed in bureaucratic thinking patterns, lacking sense of responsibility and practical investigation in solving problems. They work depending on their sensations and experience instead of going to the grass roots, so they know little about the problems of grass roots, lacking initiative enthusiasm; and forms the habit of nonfeasance gradually.

2) The power is regulated; the motivation is deficient

In recent years, the central government has rectified the construction of party styles vigorously. As a result, the rights and benefits of party members and cadres are specified, and some party cadres find it is difficult to adapt to the new situation. In the environment of lacking invisible benefits, the cadres lost work proactivity gradually. Under the pressure of current administrative accountability, some cadres are timid in their work even take negative act in the implementation of task to escape the risk of accountability.

3) Comprehensive ability is deficient; cadres have difficulty to make a difference

Lacking driving force of learning, some party members and cadres have difficulty to make a difference in the face of new and increasingly complex situations and problems. Even though they want to act positively, they are short of ability to deal with difficult problems. Besides, being forced to act positively or having arbitrary conduct makes no difference to the solution of the final problem.

\section{B. Objective Reasons}

1) The responsibility of cadres is unclear; the phenomenon of buckpassing is serious

On the one hand, because of unclear responsibility of cadres and functional departments, they are easy to be at a loss in the implementation of specific tasks even face the phenomenon of buckpassing, which will lead to inaction finally. On the other hand, due to unequal powers (especially township is more serious) and unmatched finance and affairs, it often happens that cadres have responsibilities but rights in the implementation of the task, namely administrative law enforcement power being not delegated. Therefore, in most of the time, the grassroots cadres want to make a difference but have no rights. This kind of nonfeasance is caused by improper administrative system and management, the system need to be improved.

2) Accountability mechanism is incomplete; the motivation is dampened

Now the accountability mechanism is incomplete. Because of the existence of the reversed investigation mechanism, accountability is accustomed to allow no flexibility, which causes that many legal practices in the past become illegal now. 
Some cadres fear the usual suspects, dare not to let go as follows; they would rather keep the old and follow their superiors than bear the risk of accountability afterwards. At the same time, lacking reasonable fault-tolerant mechanism, although the reform and innovation are advocated strongly, mistakes are inevitably avoided. However, once the error occurs, cadres must be responsible. Therefore, it is difficult to spire their initiative and creativity.

3) The evaluation system is unscientific; performance appraisal becomes a mere formality

Firstly, the cadre mechanism is incomplete, the evaluation of party members and cadres is just a form. It makes no difference whether they do more or less, good or bad, and it makes the assessment results meaningless and difficult to distinguish the pros and cons, let alone incentive effects. Secondly, the index of evaluation set is incomplete, the examination currently focuses more on accountability and performance evaluation. There is no index or specific measures for the recessive assessment "nonfeasance", making it difficult to use assessment to measure accountability without responsibility and evaluation without evidence. Thirdly, the utilization of the assessment results is low. For many times, the goal of examination just is a simple result but it gives effective feedback and reward through the results to make the problem of "nonfeasance" durable.

\section{4) Incentive mechanism is single; initiative is restrained}

Because the central government's regulations on party members and cadres styles are strengthened, many hidden rewards and benefits in the past are cancelled. On the one hand, without material rewards or benefits, many party cadres lose initiative power and the incentive means is single only by relying on the material incentive, lacking spirit incentive. On the other hand, due to the strengthening of the welfare standard, some party cadres even cancel all the benefits in order to avoid the risk of accountability, especially in the grassroots cadres, which makes many cadres complain and are unwilling to act positively.

\section{The COUNTERMEASURES AND SUGgestions AGAINST OFFICIALS JUST GOING THROUGH THE MOTIONS}

\section{A. To Strengthen Ideological Education and Strengthen the Service Aim}

We should strengthen the education of party members and cadres' values, and form correct "concept of power", serving as public servants to serve the people whole-heartedly. We also should implement "the three strict and honesty" strictly, strengthen responsibility consciousness, improve selfcultivation, cultivate the faith of officials just going through the motions, and correct the thought of hedonism and nonfeasance completely to be a good promising cadre. Finally, we must learn advanced models actively and maintain the awareness of serving the masses.

\section{B. To Reinforce Learning and Improve the Ability of the Management Entrepreneurship}

In the period of deepening reform comprehensively, party members and cadres should strengthen their own learning constantly, improve their professional skills as well as study and implement the relevant knowledge and skills earnestly. At the same time, they should enhance the comprehensive ability to solve complex problems and adapt to the new situation. The problems of complicated social environment, economic, livelihood, and environmental issues are always testing party members and cadres, and in order to solve the problems, cadres should improve their comprehensive ability constantly as well as the ability of innovation, for innovation is the driving force of social development, while conservatism can only be eliminated by society. Therefore, party members and cadres are required to have the ability to keep pace with the times, have the courage to face new problems, and explore new methods to be capable of outstanding achievements.

\section{To Define Responsibilities Clearly and Enhance the Sense of Responsibility}

We should firstly define job responsibilities, and handle derelict staff seriously. At the same time, we should establish responsibility lists, power lists and negative lists, and establish responsibility system, define responsibility and draw a clear distinction so as to eliminate the phenomenon of buckpassing, and put the responsibilities of subjects and oversight into practice to prevent officials' nonfeasance as well as build strong accountability for cadres' laziness on politics.

\section{To Strengthen the Supervision as well as Accountability and Rectify "Nonfeasance"}

We should strengthen daily supervision and check regularity, make accountability of nonfeasance through investigation, and broaden the channels of supervision to form diversified supervision departments such as opening public official supervision platforms of hotlines, official blog, WeChat. We should work hard to study "negative list" of officials, define the specific indicators and performance of nonfeasance to build serious accountability for cadres of inaction, and explore the mechanism of eliminating officials to form a scientific restriction mechanism of accountability finally.

\section{E. To Establish A Scientific Evaluation Mechanism and Improve the Enthusiasm of the Officers}

We should improve the performance appraisal system, and establish power lists, negative lists and the responsibility lists of party members and cadres to further clarify refined lists of nonfeasance, judging standards and treating methods. We also should link the results with evaluation, promotion and discipline to form the personnel direction of "using the capable ones, relief the incapable ones". Besides, we should reinforce the assessment and supervision, and prevent unfair phenomena to form scientific and reasonable assessment results eventually.

\section{F. To Combine Guidance with Incentive and Create the Atmosphere of "Officials Are Willing to Work"}

We should establish a reasonable incentive mechanism and combine performance management with salary system of civil servants to let cadres have initiative to act positively, and make a strict distinction between the incentive effect of "more or less" as well as "good or bad" to make people more willing to 
do things have more passion to work. At the same time, we should establish reasonable fault-tolerant mechanism and encourage cadres to work and start up business. Inevitably, there will be some mistakes, and we should establish impunity to distinguish these mistakes strictly to leave cadres the space of practicing boldly and innovatively, and create a good atmosphere of advocating success and being tolerant of failure.

\section{CONCLUSION}

In a word, there is a necessary connection between the development trend and serious politics. While intensifying anti-corruption efforts, it becomes an important and urgent task of how to solve the problem of officials just going through the motions and establish the safeguard mechanism of "officials just going through the motions". Of course, the problem can not be solved overnight, we need to improve the relevant supporting reform, establish long-term mechanism of inaction, and encourage the country to explore actively, innovate the approaches of cadre management to establish the political environment of that " the official is willing to act positively" in the whole society.

\section{REFERENCES}

[1] Shi Xuefeng. The Problems and Its Regulation of "Officals Just Going through the Motions" in the Practice of Strengthening Party SelfDiscipline. [J]. Yunnan Social Sciences, 2015 (2).

[2] Hao Chunlu. The Questionnaire of "Officals Just Going through the Motions" [J]. Theory Horizon, 2015

[3] He Bingwen. The Reflection on the Problem that "Officals Just Going through the Motions" [J]. Digest of Managerment Science, 2015 (1).

[4] Hao Yanjie. Being Imperative to Renovate That "Officals Just Going through the Motions" [J]. Youthful Years, 2015 (15).

[5] Chinese Public Administration "Editorial Department". Regulating the Styles of "Officals Just Going through the Motions" and Laziness and Neglect of Administrative Duties [J]. Chinese Public Administration, 2015 (4).

[6] Hao Yanjie. It Is Imperative to Renovate "Officals Just Going through the Motions" [J]. Youthful Years, 2015 (15) 